\title{
Keyword Analysis of Arboretums and Botanical Gardens Using Social Big Data
}

\author{
Hyun-Tak Shin ${ }^{1}$, Sang-Jun Kim², and Jung-Won Sung ${ }^{3 *}$ \\ ${ }^{1}$ Senior researcher, DMZ Botanic Garden, Korea National Arboretum, Yanggu 24564, Korea \\ ${ }^{2}$ Post-doctoral associate, DMZ Botanic Garden, Korea National Arboretum, Yanggu 24564, Korea \\ ${ }^{3}$ Assistant manager, Division of Planning and Operations, National Baekdudaegan Arboretum, Bongwha 35208, Korea
}

\section{ABSTRACT}

This study collects social big data used in various fields in the past 9 years and explains the patterns of major keywords of the arboretums and botanical gardens to use as the basic data to establish operational strategies for future arboretums and botanical gardens. A total of 6,245,278 cases of data were collected: 4,250,583 from blogs (68.1\%), 1,843,677 from online cafes (29.5\%), and 151,018 from knowledge search engine (2.4\%). As a result of refining valid data, 1,223,162 cases were selected for analysis. We came up with keywords through big data, and used big data program Textom to derive keywords of arboretums and botanical gardens using text mining analysis. As a result, we identified keywords such as 'travel', 'picnic', 'children', 'festival', 'experience', 'Garden of Morning Calm', 'program', 'recreation forest', 'healing', and 'museum'. As a result of keyword analysis, we found that keywords such as 'healing', 'tree', 'experience', 'garden', and 'Garden of Morning Calm' received high public interest. We conducted word cloud analysis by extracting keywords with high frequency in total 6,245,278 titles on social media. The results showed that arboretums and botanical gardens were perceived as spaces for relaxation and leisure such as 'travel', 'picnic' and 'recreation', and that people had high interest in educational aspects with keywords such as 'experience' and 'field trip'. The demand for rest and leisure space, education, and things to see and enjoy in arboretums and botanical gardens increased than in the past. Therefore, there must be differentiation and specialization strategies such as plant collection strategies, exhibition planning and programs in establishing future operation strategies.

Keywords: Garden of Morning Calm, opinion mining, text mining analysis, trip

\section{Introduction}

The first space in South Korea created to test and exhibit plants was the test garden installed in Hongneung and Gwangneung to test and develop tree species for afforestation in 1922. This was the beginning of arboretums in Korea. Then in the 1960s, Korea's first private arboretum, Cheollipo Arboretum, was established by Carl Ferris Miller, followed by Seoul National University Gwanak Arboretum established by professor Chang Bok Lee, which gave rise to arboretums with modern functions and roles (Kang, 2012). Accordingly, Korea Forest Service perceived the urgent need to establish a national arboretum to systematically preserve and study forest biospecies in Korea and lead interaction and cooperation among arboretums that are already established, ultimately expanding the Arboretum Division of the Jungbu Forestry Examination Site in Forestry Research Institute into an independent national arboretum in 1999 (Lee, 2008).

In the 2000s, which is the time in which the number of arboretums increased, 20 new public and private arboretums were established. Upon entering the era of $\$ 10$ thousand per capita income, establishing the Act on the Creation and Furtherance of Arboretums and Gardens, im-

Received: February 5, 2020, Revised: February 12, 2020, Accepted: March 5, 2020

First author: Hyun-Tak Shin, twinshin@korea.kr, (D) https://orcid.org/0000-0002-7164-5338

*Corresponding author: Jung-Won Sung, onsulove2036@hanmail.net, (1) https://orcid.org/0000-0001-8272-9695 
plementing the five-day workweek policy and improving the leisure culture, the interest in and demand for arboretums and botanical gardens rapidly increased, raising the need for various analyses to establish effective operational strategies (Kang, 2012).

Meanwhile, many kinds of data using big data are now used in various fields such as society, economy, culture and arts, as the development of equipment and techniques such as opinion mining and text mining has enabled people to use multiple data that they could not process Choi and Choi, 2015). However, no trend analysis has been conducted thus far on how the social, economic and cultural interests in arboretums and botanical gardens have changed. In particular, among big data analysis, social big data analysis extracts information by collecting and classifying countless data from various paths of social media with real stories of producers or consumers, which is most efficient in determining thoughts, inconveniences, desires and behaviors of consumers (Lim and Park, 2015). In fact, many places are using social big data analysis to establish operational strategies, develop and publicize programs, and analyze user behavior. Therefore, this study is conducted to find the keyword patterns of arboretums and botanical gardens using social big data collected from blogs, cafes, knowledge search, etc. in the last 9 years, select the most relevant search words, and determine whether social, economic and cultural changes of arboretums and botanical gardens that occur real-time or will occur in the near future can be predicted in advance through sentiment analysis. Furthermore, we will trace the course of arboretums and botanical gardens and explain the patterns of change to use the results as the basic data to establish operational strategies for future arboretums and botanical gardens.

\section{Research Methods}

\section{Theoretical considerations}

\section{Social big data}

With the development of 5G information technology and increasing interest and attention in the internet, mobile platforms and social media, big data is used as a tool to solve social problems in various fields such as society, economy, culture and arts. Many countries in the world are using big data, which performs a key role in determining the flow of the past and present through social media and predicting and solving future problems based on the ripple effect on the public and private sectors (Song, Song, and Cheon, 2015). Moreover, social media is used by firms as a channel for interaction and communication with researchers in addition to publicity, which results in improving the quality of innovation with swarm creativity (Chun, 2015). The Korean government is actively implementing use of big data in various fields to achieve creative economy, anticipating ripple effects such as efficiency in the administrative system and economic revitalization (Hong, 2014). Meanwhile, the results of social big data analysis are obtained by the producers searching keywords or related words in the document and analyzing their significance. Sentiment analysis such as opinion mining as well as text mining is performed, followed by statistics analysis and network analysis. This has the form of data that can increase reliability depending on age, gender and occupation (Chun, 2015). Longitudinal and cross-sectional studies that have been conducted were used effectively in determining the relationship between groups and individuals in terms of determined factors and variables, but are limited in analyzing the correlation of mutual information exchange that has been discussed in individual documents online (Song, Song, and Cheon, 2015). To make up for this deficiency, social media among big data analytics enables users to determine the views and thoughts of consumers based on abundant data, and when used along with offline complete enumeration survey, it would be possible to predict and cope with social, cultural and economic concerns that are currently causing problems based on reliable data.

\section{Cases of using social big data}

The development of rapidly changing information technology is expanding accessibility to social media in various channels such as internet and mobile. In particular, various users are producing a great amount of data on a real-time basis using internet or mobile-based smart devices, and it became possible to capture and analyze the trends of the 
times in different fields through collection and analysis of data (Seo and Koh, 2014). This is used as a tool to more quickly approach technological development and customer needs by analyzing user consciousness, tendencies and emotions based on collected data and obtaining objective information (Chang, 2015). Moreover, social big data is used actively in various fields such as verification of diplomatic tools (Choi and Kim, 2016), image assessment (Hong and Oh, 2016), public relations strategies (Lee et al., 2015; Oh et al., 2015), analysis of stock prices (Kim et al., 2014), etc. In particular, opinion mining among sentimental analyses of text mining is used to determine the positive and negative perceptions and tendencies of users, come up with problems and improve them. Furthermore, a detailed analysis of collected data on social media shows a considerably high ratio of subjective opinions from individuals. Thus, compared to existing documents or publications, applying opinion mining will help obtain objective and rational data (Choi and Choi, 2015; Jang, 2013; Kim et al., 2014). Song, Noh, and Lee (2015) proposed a service model recommending cultural contents such as movies, plays and music according to individual tastes and sentiments using big data of social media. It is also used in various fields such as sentiment analysis on social issues (Kang et al., 2015), prediction of stock price fluctuations (Kim et al., 2014), fashion marketing with analysis on user opinions (Lee et al., 2014), etc.

\section{Research content and methods}

\section{Content}

We classified the keywords of arboretums and botanical gardens by the trends of times from 2010 to 2018, and conducted text mining, word cloud analysis, and sentiment analysis (Fig. 1). This study collected public opinions about big data on social media as the data and used the text mining technique. Moreover, we checked the main trends of arboretums and botanical gardens through keywords by year and determined the public awareness according to time. The process of big data analysis was carried out in four steps as shown in Fig. 1: data collection, data preprocessing, text mining, and sentiment analysis (opinion mining).

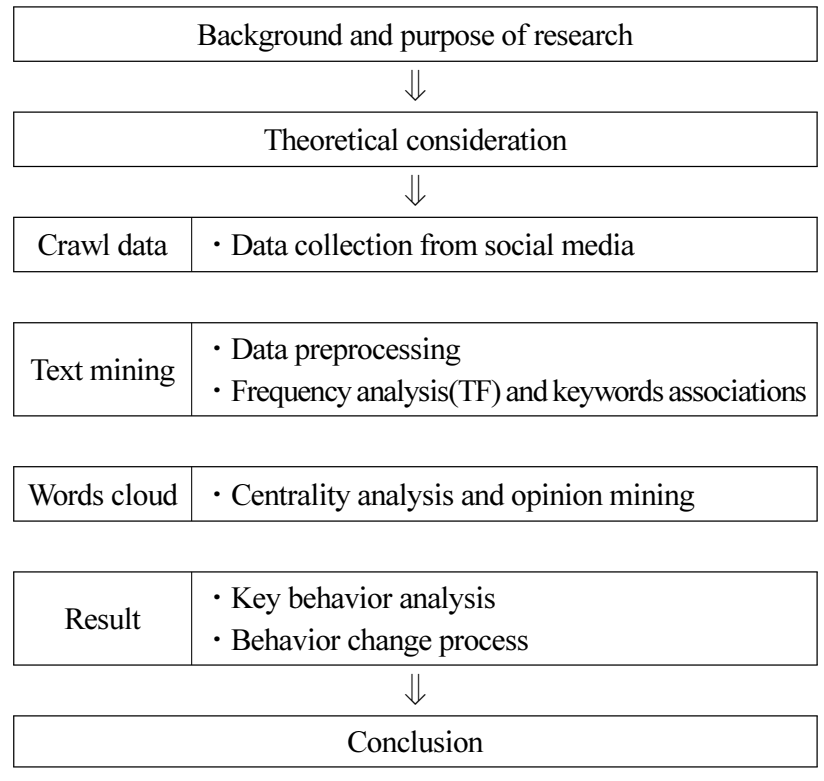

Fig. 1. Flow diagram of study process.

\section{Methods}

\section{(1) Data collection}

We used big data program Textom (http://www.textom.c o.kr) to collect data for text mining analysis and word cloud analysis, and collected text data including keywords 'arboretum' and 'botanical garden' in the original texts of six social media such as Naver Blog, Café, Knowledge IN as well as Daum Blog, Café, and Instagram.

Data was collected for 9 years from 2008 to 2018, searching keywords of arboretums and botanical gardens. Moreover, we determined the user motivations for visit, purpose, and expectations about arboretums and botanical gardens. Social Matrix provides only documents (Docs) related to keywords that are to be analyzed via analytical engine comprised of text mining and natural language processing technique. Keywords are divided into related words and sentiment analysis. Related word analysis determines the trends and characteristics of users by extracting the most relevant word among those used in keywords. Sentiment analysis classifies subjective data such as opinions, attitudes and tendencies of online users about certain words according to their sentiment by categorizing the expressions into positive, negative and neutral (Lim and Park, 2015). Data provided on Social Matrix includes all original texts including keywords to analyze, and thus information that is not directly related to research is also likely to be 
obtained as a result. Accordingly, we analyzed only the original text related to keywords we intend to analyze in this study by undergoing the filtering process of unnecessary endings such as parts of speech and affixes.

\section{(2) Text mining analysis}

We used big data program Textom to come up with keywords of arboretums and botanical gardens through big data and text mining analysis. To increase accuracy of collected data, we filtered the search words and excluded unnecessary parts of speech and affixes that are not related to this study. Frequency analysis is counting how many times the relevant search words appear in the collected news, which in this study was used to distinguish keywords and related search words. Moreover, we visually promoted understanding using word cloud (http://wordcloud.kr) to find out the singularities of keywords that are not derived in frequency analysis.

\section{Results and Discussion}

\section{Results of data collection}

Collected data is as shown in Fig. 2. There were total $6,245,278$ cases of data collected by year from 2010 to June 2018. Big data program Textom can randomly sum- marize and collect valid data excluding unreadable missing values that are not texts, such as images, photos, mathematical symbols, programming languages, etc. on social media during the selection period (Woo and Suh, 2017) and thus selected total 1,223,162 cases for analysis. The amount of data collected by year was the biggest in 2016 with 171,135 cases (14.0\%), and the smallest in 2010 with 100,457 cases (8.2\%). In particular, the collection period in 2018 was short, just 6 months, and thus we did not separately compare with the amount of data collected by year. Overall, social data showed a continuous increase.

\section{Results of text mining analysis}

We came up with high frequency keywords by year after data refining and selected keywords with reference to the word cloud, and as a result, 30 top frequency keywords are as shown in Table 1, Fig. 3 and Fig. 4. The result of analyzing social keywords of arboretums and botanical gardens by year showed that the keyword 'garden' constantly appeared since 2010. As the Anmyeondo International Flower Exhibition was held in 2009, presenting various things to see and enjoy, gardens began to receive public attention and were searched as a keyword on social media such as blogs, cafes, knowledge search, etc., In particular, the search rapidly increased by 1,445 cases compared to the previous year when the Suncheon Bay International

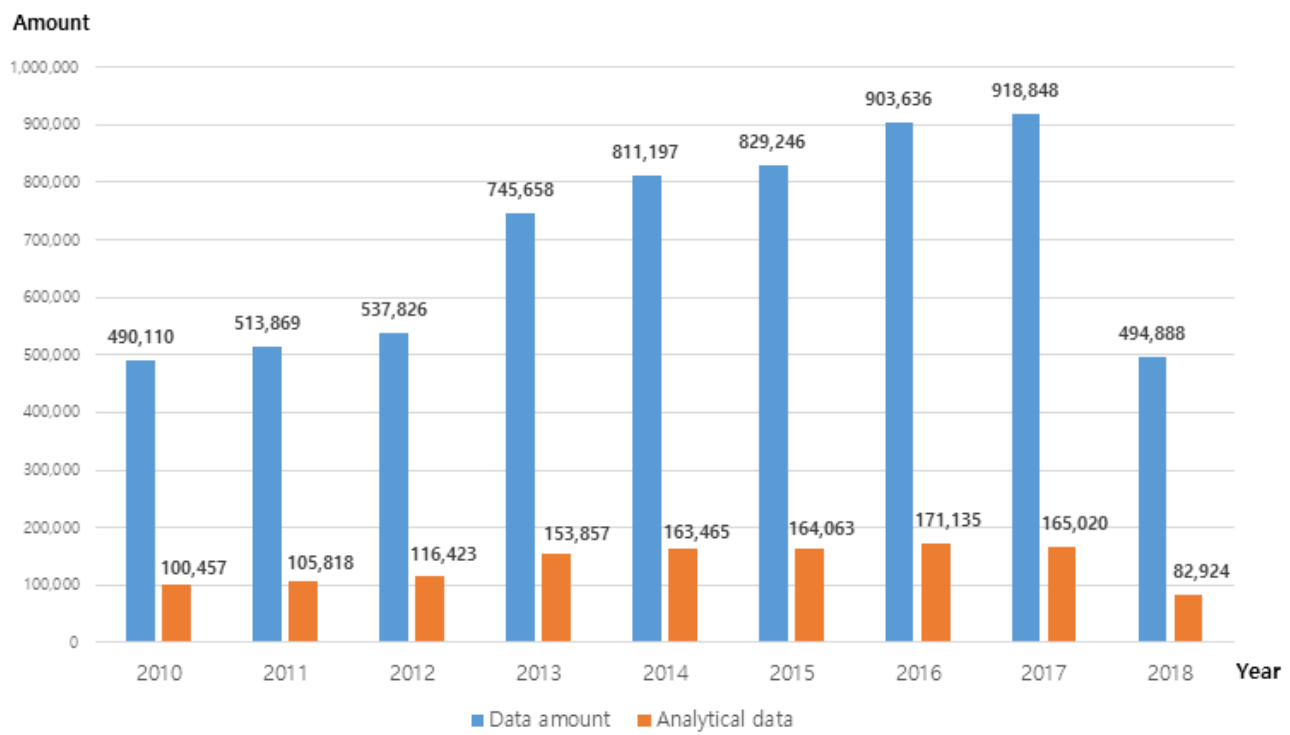

Fig. 2. Data collection from social media with keywords of arboretums and botanical gardens over years. 
Table 1. Frequency of behavior-related keywords about arboretums and botanical gardens

\begin{tabular}{|c|c|c|c|c|c|}
\hline \multicolumn{2}{|l|}{2010} & \multicolumn{2}{|l|}{2011} & \multicolumn{2}{|l|}{2012} \\
\hline Keyword & Frequency & Keyword & Frequency & Keyword & Frequency \\
\hline Arboretum & 30,569 & Arboretum & 32,568 & Arboretum & 33,580 \\
\hline Botanical garden & 13,313 & Botanical garden & 13,019 & Botanical garden & 13,074 \\
\hline Garden of Morning Calm & 9,111 & Garden of Morning Calm & 9,377 & Garden of Morning Calm & 10,237 \\
\hline Tree & 4,004 & Tree & 4,280 & Tree & 4,447 \\
\hline Trip & 3,166 & Trip & 3,425 & Jeju Island & 4,154 \\
\hline Rooms & 2,893 & Autumn & 2,798 & Trip & 3,636 \\
\hline Course & 2,644 & Gapyeong & 2,588 & Walk & 3,240 \\
\hline Garden & 2,554 & Picnic & 2,499 & Gapyeong & 2,982 \\
\hline Autumn & 2,304 & Rooms & 2,478 & Autumn & 2,958 \\
\hline Museum & 2,129 & Museum & 2,365 & Mountain & 2,727 \\
\hline Gwangneung Arboretum & 2,046 & Course & 2,239 & Picnic & 2,585 \\
\hline Picnic & 2,045 & Mulhyanggi Arboretum & 2,217 & Pension & 2,463 \\
\hline Mulhyanggi Arboretum & 2,027 & Gwangneung Arboretum & 2,172 & Daegu Arboretum & 2,450 \\
\hline Children & 1,958 & Daegu Arboretum & 2,106 & Festival & 2,149 \\
\hline Scenery & 1,907 & Garden & 1,844 & Mulhyanggi Arboretum & 2,120 \\
\hline Wildflowers & 1,859 & Weather & 1,682 & Gwangneung Arboretum & 2,049 \\
\hline Daegu Arboretum & 1,816 & Children & 1,674 & Weather & 1,982 \\
\hline Weather & 1,515 & Scenery & 1,556 & Garden & 1,920 \\
\hline Beauty & 1,321 & Wildflowers & 1,524 & Course & 1,916 \\
\hline Cheollipo Arboretum & 1,258 & Republic of Korea & 1,524 & Halla Arboretum & 1,645 \\
\hline Pocheon & 1,175 & Halla Arboretum & 1,407 & Scenery & 1,612 \\
\hline Admission fee & 1,102 & Pocheon & 1,373 & Cheollipo Arboretum & 1,531 \\
\hline Halla Arboretum & 1,073 & Recreation forest & 1,322 & Rooms & 1,476 \\
\hline National Arboretum & 1,053 & Hiking & 1,216 & Pocheon & 1,469 \\
\hline Hiking & 1,019 & Cheollipo Arboretum & 1,200 & Children & 1,458 \\
\hline Place & 954 & Gyeongnam & 1,181 & Museum & 1,451 \\
\hline Natural Recreation Forest & 943 & Admission fee & 1,180 & Admission fee & 1,399 \\
\hline Maple & 911 & Pyeonggang Botanical Garden & 1,063 & Festival & 1,336 \\
\hline Pyeonggang Botanical Garden & 904 & Anmyeondo & 1,021 & Wildflowers & 1,196 \\
\hline Experience & 884 & Experience & 920 & Experience & 1,181 \\
\hline \multicolumn{2}{|l|}{2013} & \multicolumn{2}{|l|}{2014} & \multicolumn{2}{|l|}{2015} \\
\hline Keyword & Frequency & Keyword & Frequency & Keyword & Frequency \\
\hline Arboretum & 48,026 & Arboretum & 49,111 & Arboretum & 47,647 \\
\hline Botanical garden & 16,166 & Garden of Morning Calm & 17,945 & Garden of Morning Calm & 19,282 \\
\hline Garden of Morning Calm & 15,389 & Botanical garden & 15,699 & Botanical garden & 14,142 \\
\hline Tree & 6,129 & Tree & 6,976 & Tree & 7,087 \\
\hline Trip & 5,025 & Trip & 5,470 & Trip & 5,653 \\
\hline Autumn & 4,713 & Autumn & 5,141 & Autumn & 5,586 \\
\hline Picnic & 4,165 & Picnic & 4,941 & Picnic & 5,055 \\
\hline Festival & 4,033 & Recreation forest & 3,976 & Weather & 4,027 \\
\hline Pension & 3,612 & Daegu Arboretum & 3,880 & Daegu Arboretum & 3,738 \\
\hline Gwangneung Arboretum & 3,392 & Gwangneung Arboretum & 3,734 & Recreation forest & 3,682 \\
\hline Garden & 3,365 & Weather & 3,252 & Gwangneung Arboretum & 3,419 \\
\hline Daegu Arboretum & 3,310 & Mulhyanggi Arboretum & 3,153 & Garden & 3,145 \\
\hline Mulhyanggi Arboretum & 3,105 & Garden & 3,150 & Rooms & 3,091 \\
\hline Weather & 3,097 & Pocheon & 2,769 & Festival & 2,995 \\
\hline Children & 2,881 & Camping ground & 2,653 & Halla Arboretum & 2,741 \\
\hline
\end{tabular}


Table 1. (continued)

\begin{tabular}{|c|c|c|c|c|c|}
\hline \multicolumn{2}{|l|}{2013} & \multicolumn{2}{|l|}{2014} & \multicolumn{2}{|l|}{2015} \\
\hline Keyword & Frequency & Keyword & Frequency & Keyword & Frequency \\
\hline Course & 2,627 & Admission fee & 2,627 & Admission fee & 2,655 \\
\hline Scenery & 2,209 & Course & 2,485 & Children & 2,636 \\
\hline Cheollipo Arboretum & 2,111 & Halla Arboretum & 2,460 & Walk & 2,564 \\
\hline Admission fee & 2,083 & Rooms & 2,454 & Mulhyanggi Arboretum & 2,316 \\
\hline Halla Arboretum & 2,080 & Cheollipo Arboretum & 2,306 & Course & 2,316 \\
\hline Festival & 1,999 & Children & 2,226 & Restaurant & 2,303 \\
\hline Museum & 1,996 & Walk & 2,075 & Nami Island & 2,292 \\
\hline Pocheon & 1,880 & Festival & 2,039 & Experience Class & 2,215 \\
\hline Experience & 1,775 & Zoo & 2,031 & Visiting experience learning & 2,168 \\
\hline Walk & 1,534 & Museum & 1,983 & Scenery & 2,009 \\
\hline Program & 1,517 & Scenery & 1,921 & Destination & 2,003 \\
\hline Wildflowers & 1,441 & Bicycle & 1,840 & Cheollipo Arboretum & 1,898 \\
\hline Recreation forest & 1,412 & Anmyeondo & 1,811 & Date & 1,813 \\
\hline Jeju Island & 1,397 & Jade Garden & 1,715 & Summer & 1,813 \\
\hline Jade Garden & 1,388 & Experience & 1,642 & Bicycle & 1,772 \\
\hline \multicolumn{2}{|l|}{2016} & \multicolumn{2}{|l|}{2017} & \multicolumn{2}{|l|}{2018} \\
\hline Keyword & Frequency & Keyword & Frequency & Keyword & Frequency \\
\hline Arboretum & 48,566 & Arboretum & 47,514 & Arboretum & 23,568 \\
\hline Garden of Morning Calm & 19,545 & Garden of Morning Calm & 15,953 & Garden of Morning Calm & 7,810 \\
\hline Botanical garden & 14,267 & Botanical garden & 13,564 & Botanical garden & 7,394 \\
\hline Trip & 7,326 & Trip & 7,426 & Restaurant & 4,268 \\
\hline Tree & 7,147 & Tree & 6,564 & Trip & 3,820 \\
\hline Picnic & 5,853 & Autumn & 5,353 & Tree & 3,340 \\
\hline Autumn & 4,994 & Picnic & 5,261 & Picnic & 2,622 \\
\hline Weather & 4,072 & Restaurant & 5,052 & Function & 2,439 \\
\hline Restaglurant & 3,904 & Daegu Arboretum & 3,997 & Daegu Arboretum & 1,959 \\
\hline Gwangneung Arboretum & 3,884 & Gwangneung Arboretum & 3,751 & Halla Arboretum & 1,938 \\
\hline Daegu Arboretum & 3,734 & Garden & 3,637 & Gwangneung Arboretum & 1,898 \\
\hline Garden & 3,601 & Weather & 3,506 & Weather & 1,724 \\
\hline Pension & 3,458 & Pension & 3,430 & Garden & 1,575 \\
\hline Children & 3,251 & Children & 3,084 & Festival & 1,327 \\
\hline Recreation forest & 3,231 & Halla Arboretum & 2,959 & Walk & 1,307 \\
\hline Course & 2,884 & Function & 2,882 & Fine dust & 1,295 \\
\hline Museum & 2,815 & Walk & 2,835 & Course & 1,198 \\
\hline Admission fee & 2,750 & Admission fee & 2,686 & Admission fee & 1,148 \\
\hline Halla Arboretum & 2,703 & Festival & 2,638 & Cheollipo Arboretum & 1,137 \\
\hline Walk & 2,648 & Course & 2,549 & Recreation forest & 1,126 \\
\hline Pocheon & 2,606 & Recreation forest & 2,443 & Children & 1,071 \\
\hline Mulhyanggi Arboretum & 2,227 & Parking & 2,298 & Parking & 1,054 \\
\hline Nami Island & 2,218 & Rooms & 2,195 & Rooms & 1,050 \\
\hline Date & 2,157 & Experience & 2,135 & Experience & 1,047 \\
\hline Visiting experience learning & 1,911 & Mulhyanggi Arboretum & 1,951 & Hanbat Arboretum & 1,032 \\
\hline Summer & 1,902 & Sejong & 1,933 & Cherry Blossom & 1,031 \\
\hline Cheollipo Arboretum & 1,886 & Museum & 1,911 & Scenery & 998 \\
\hline Theoretical education & 1,869 & Scenery & 1,861 & Mulhyanggi Arboretum & 949 \\
\hline Light festival & 1,866 & Cheollipo Arboretum & 1,831 & National Arboretum & 912 \\
\hline Destination & 1,860 & Program & 1,821 & Sejong & 887 \\
\hline
\end{tabular}




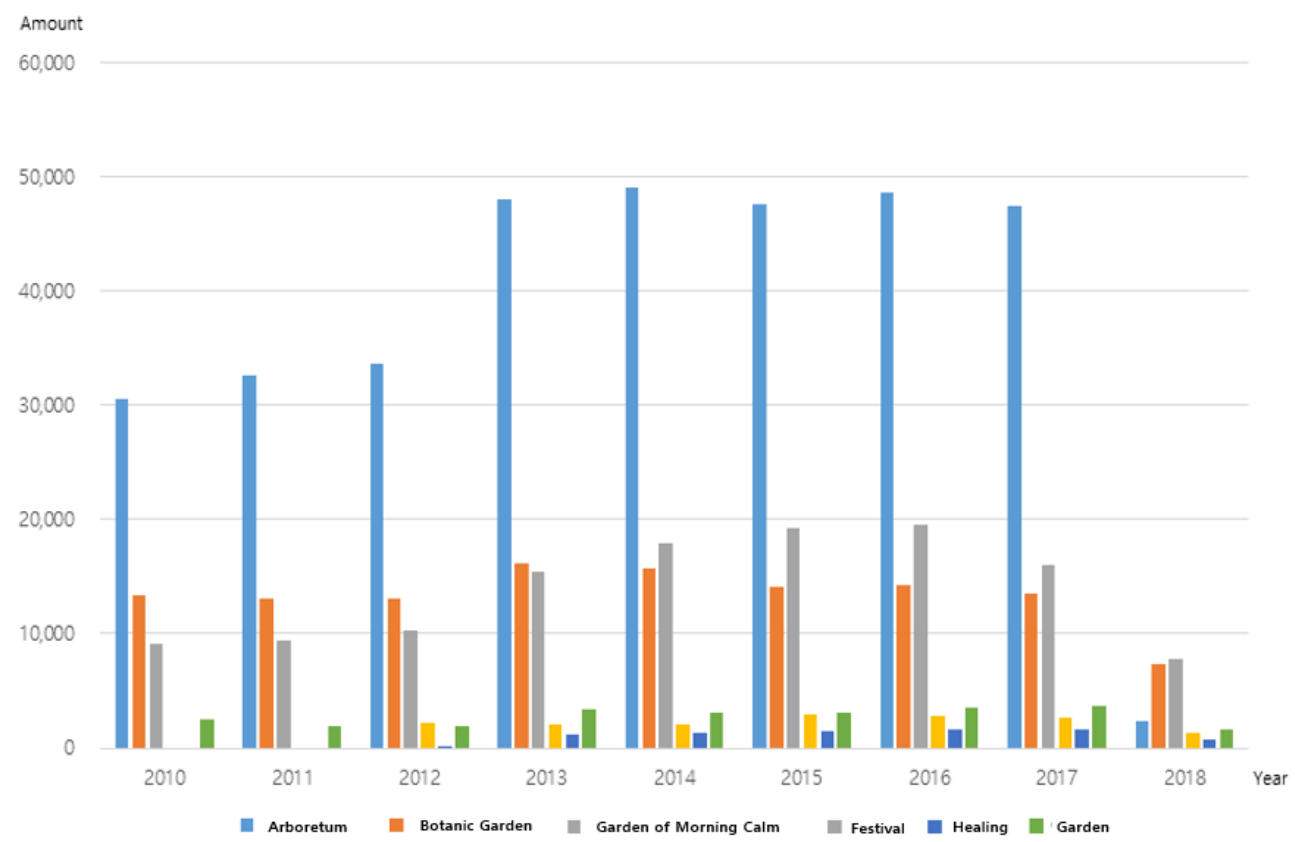

Fig. 3. Search trends of major keywords related to arboretums and botanical gardens over years.

Garden Expo was held in 2013. With the designation of the first national garden in Korea in 2015, interest in gardens is expected to continuously increase.

As the keyword 'healing' first appeared in 2012, 'travel' and 'healing' tended to increase at the same time (Fig. 3). The word 'healing' which had been used only by a few people in the past, surpassed the craze of well-being that began since the early 2000 s and became a big trend overall such as society, culture and economy (Oh, 2016). This trend spread out to various fields such as arboretums and botanical gardens, temple stay and forest healing programs, and was even applied to tourism. Traveling for 'healing' implies that the pattern of travel in Korea is gradually changing from visual tourism focused on getting away from the city to realistic lifestyle tourism focused on relationship building such as direct experience and festivals. Considering the change in such trend, it is necessary to well reflect the rapidly changing trend of times by constantly monitoring individual tendencies that pursue 'healing' in arboretums and botanical gardens through social media such as blogs, cafes, knowledge search, etc., and to develop and supply exhibition and education programs based on the intrinsic culture of the region.

Since 2013, public interest in 'arboretum' increased significantly, but that in 'botanical garden' seemed to have declined. This suggests that the perception and interest have changed, regarding nature not as an object of learning but as an object to experience. Furthermore, keywords such as 'tree' and 'experience' related to 'arboretum' also showed high frequency, implying that national interest and demand have increased for education and experience programs held in arboretums such as Gwangneung Forest bird exploring, professional exhibition garden interpretation, forest prenatal program, summer forest camp, etc. In particular, the Happiness Promotion Program enables people that are underprivileged in terms of nature-related activities due to physical and financial difficulties to experience the diverse functions of forests, thereby expanding the base for educational services by increasing the scope of beneficiaries and operating customized education programs. Moreover, the $\mathrm{O}_{2}$ Program boosts energy into military life by linking forest experience programs for Korean soldiers. As such, arboretums and botanical gardens provide the right functions of forests in various fields, helping promote welfare for citizens.

In 2016, the keyword 'Garden of Morning Calm' showed the highest frequency, due to the publicity effect of filming location (movie title "The Letter") and theme-based exhibition centers that capture visitors' attention such as Starlight Garden Festival and Rose Festival, as well as high accessibility with its location in the outskirts of the city. 


\section{Results of word cloud analysis}

We conducted word cloud analysis after data mining of texts in blogs, cafes, knowledge search, etc. with keywords of arboretums and botanical gardens. We extracted keywords with high frequency in the titles of total $6,245,278$ cases, and bigger text indicates higher frequency (Fig. 4). As such, the public perceived arboretums and botanical gardens as spaces for rest and leisure such as 'travel', 'picnic' and 'recreation'. We could also discover public interest in educational aspects through keywords such as' experience' and 'field trip'. Moreover, various things to see and enjoy in arboretums and botanical gardens were also mentioned, such as 'zoo', 'museum' and 'festival', indicating that arboretums and botanical gardens must develop differentiated exhibition and education programs for each region and establish operational strategies that reflect customer needs.

\section{Results of sentiment analysis}

We intended to conduct opinion mining, which is a technique of sentiment analysis among the techniques used to analyze the meaning of online documents by users for social big data analysis, and determine the sentiments about arboretums and botanical gardens (Fig. 5). There were more positive expressions about arboretums, whereas negative expressions rarely appeared. There were 18,002 cases (89\%) of positive keywords about arboretums by the public, such as 'relaxing', 'healing' and 'comfortable', indicating that arboretums were perceived positively by the public

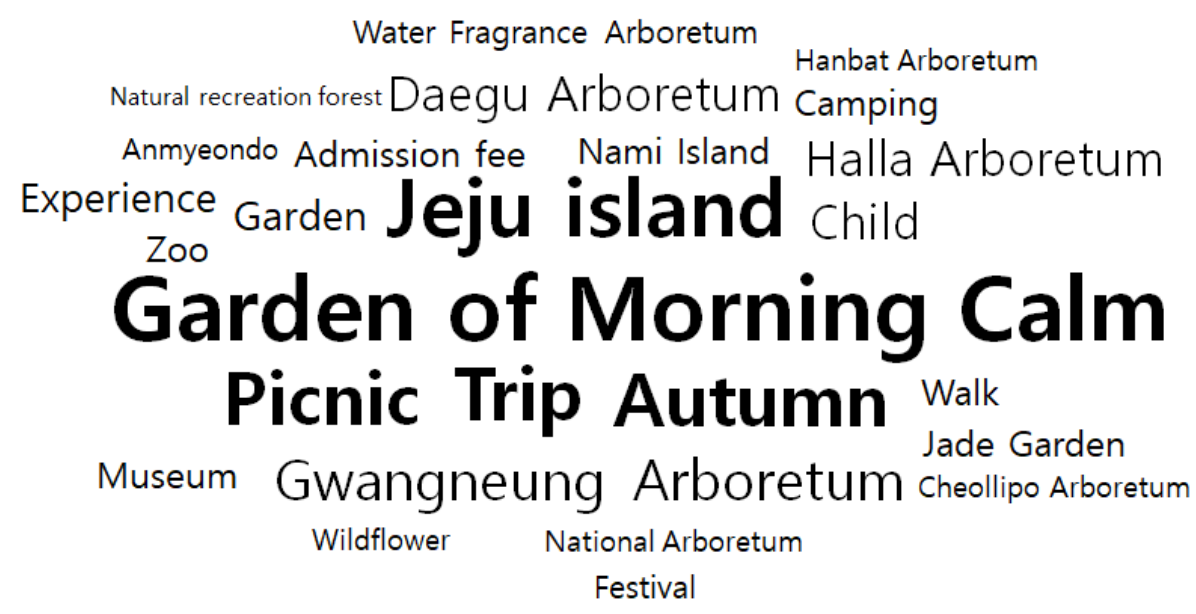

Fig. 4. Word cloud made of keywords related to arboretums and botanical gardens.

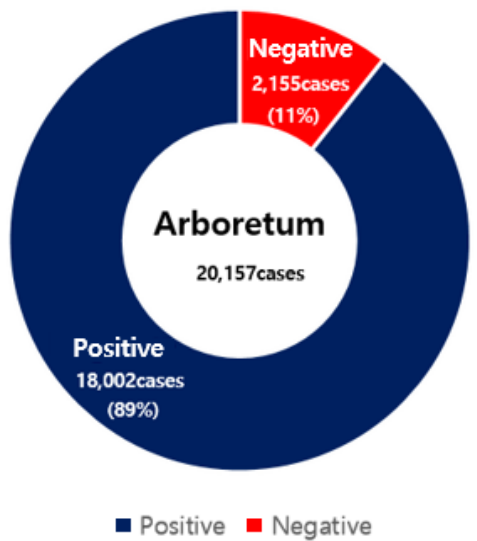

(A) Arboretums

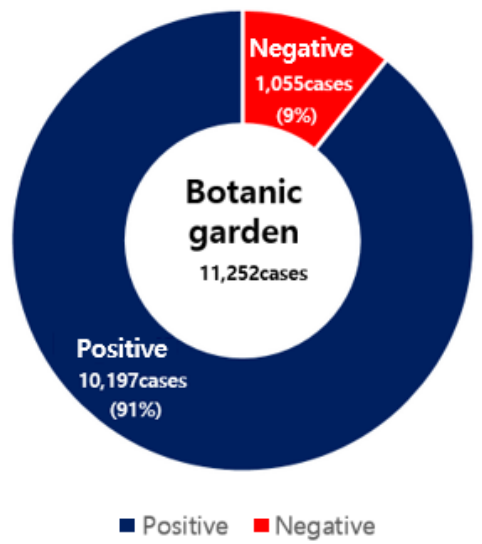

(B) Botanic gardens

Fig. 5. Sentiment analysis for arboretums (A) and botanic gardens (B). 
as a rest area that provide mental comfort away from exhausting daily life. On the other hand, there were 2,155 cases $(11 \%)$ of negative keywords about the high entrance fees and the management state of arboretums that fall short of the fees, such as 'expensive', 'disappointing' and 'damaged'. As a result of analysis by year, the ratio of negative keywords increased by $4 \%$ in 2011 compared to the previous year, which is the increase in the negative keyword 'inadequate' about facility and operation (Fig. 6). Recently, the ratio of positive keywords increased such as 'relaxing' along with the positive keyword 'substantial' about aesthetic satisfaction as well as experience programs and exhibitions. Overall, regarding sentiment words about arboretums, admission fees vary depending on the host and the purpose of foundation and thus may not be adequate for description. However, considering the public view about the management state, arboretums and botanical gardens must inspect their sites and establish management plans to preserve the forest resources and improve the image as a place for exhibitions and education among the public.

There were 10,197 cases $(91 \%)$ of positive keywords by the public about botanical gardens, some of them about the landscape of botanical gardens such as 'pretty', 'fabulous' and 'marvelous', as well as 'unique' for novel attempts like a maze park or jungle adventure. On the other hand, there were 1,055 cases $(9 \%)$ of negative keywords such as 'inadequate' and 'boring' due to dull compositions and insufficient amenities, as well as negative keyword 'damaged'

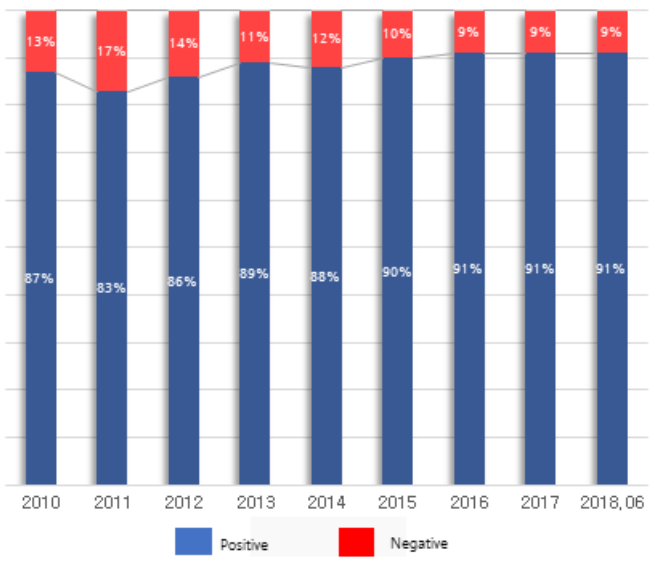

(A) Arboretums due to poor management (Fig. 5). As a result of analysis by year, there was a keyword 'awful' in 2011 in terms of operation, due to noise from remodeling and decreased satisfaction (Fig. 6). Lack of things to see and enjoy compared to the size of the venue led to dissatisfaction about high admission fees, giving rise to new negative keywords such as 'nothing to see', 'cannot see' and 'disappointing'. On the other hand, the increase of positive keywords such as 'pretty' and 'fabulous' related to festivals and events as well as natural landscapes was used as a tool to promote positive awareness about botanical gardens. The public seems to prefer dynamic elements such as various games, experiences and recreation away from the simple form of exhibitions and viewing of landscape elements. Therefore, botanical gardens must develop and publicize various events, exhibitions and education programs using plants of forest resources, and strive to provide desirable forest services for the public.

\section{Conclusion}

This study was conducted to determine whether social, economic and cultural changes of arboretums and botanical gardens can be predicted using social big data collected from blogs, cafes, knowledge search, etc. in the last 9 years. Moreover, we traced the courses of arboretums and botanical gardens and explained the patterns of change to use

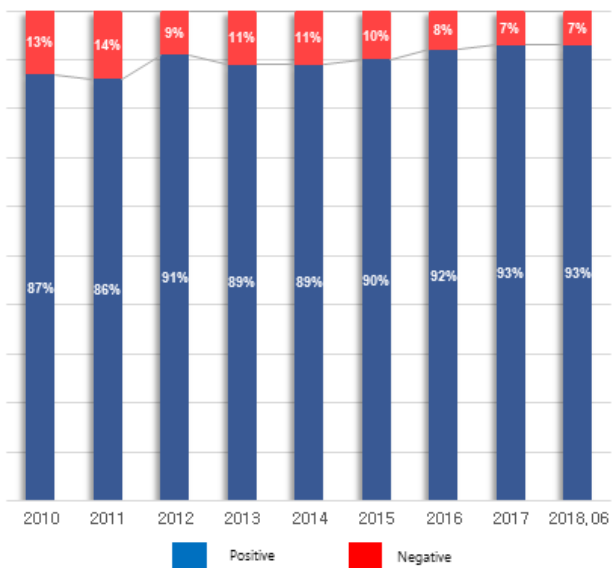

(B) Botanic gardens

Fig. 6. Changes in the distribution of sentiment analysis for arboretums $(A)$ and botanic gardens $(B)$ over years. 
as the basic data to establish operational strategies for future arboretums and botanical gardens. As a result of refining collected data, total 1,223,162 cases were selected for analysis. By year, there were 171,135 cases in 2016 $(14.0 \%)$ and 100,457 cases in 2010 (8.2\%), and social data tended to increase constantly. This indicates that users are showing more interest due to the publicity effect of various things to see and enjoy through education/experience programs and exhibitions planned and carried out in arboretums and botanical gardens, along with the increasing base of consumers using Naver and Daum Blog, Café, Knowledge IN and Instagram. The keywords identified included 'arboretum', 'healing', 'travel', 'experience', 'Garden of Morning Calm' and 'festival'. This implied that arboretums and botanical gardens had been merely perceived by the public as place to watch or observe, but are now perceived as a place to experience nature up close with various plants and programs such as customized forest interpretation and healing for different age groups and participants.

The keyword analysis results of arboretums and botanical gardens using social big data can be summarized as follows. First, as interest in 'healing' expanded to various fields including arboretums and botanical gardens, the form of travel in Korea changed from visible tourism focused on getting away from the city to realistic lifestyle tourism focused on relationship building such as direct experience, festivals, temple stay and forest healing programs. Arboretums and botanical gardens must strive to publicize the importance of conservation through education and exhibitions about the precious values, effects and uses of forest resources beyond providing just experiences and festivals. Second, public interest in 'tree' and 'experience' related to 'arboretum' also increased, which resulted in high national interest and demand such as having their own trees, air purifying plants, and plants that reduce particulate matter. Third, 'gardens' are showing various things to see and enjoy through national gardens and garden flower exhibitions, implying that the garden culture is spreading out according to function and space, such as development of plantation techniques for traditional Korean gardens, garden shows using Korean native plants, and tools to improve backward regions. Fourth, public interest in the keyword 'Garden of Morning Calm' increased through unique ex- hibitions and events such as Starlight Garden Festival, light festival and nightscape. This is due to the interest in events and exhibitions held in the Garden of Morning Calm at night, along with the trend of opening amusement parks, historic sites and parks at night. The results of word cloud and sentiment analysis showed that public awareness about arboretums and botanical gardens showed high positivity. This is because there is a higher demand for rest and leisure space, education and things to see and enjoy in arboretums and botanical gardens compared to the past. Thus, it is necessary to come up with a future-oriented and long-term operation roadmap for arboretums and botanical gardens to meet such demand.

Arboretums and botanical gardens must establish facilities and infrastructures so that users can feel that they are convenient and safe. They must also develop programs based on the life cycle or families by seeking diversification through program development and research, and develop and operate differentiated forest interpretation and education programs between arboretums and botanical gardens. Based on the above, it is necessary to induce constant public participation through publicity and marketing to promote awareness as a space for cultural life that provides nature-related experience and education on the value of nature. Therefore, there must be differentiation and specialization strategies such as plant collection, exhibition planning, and development of education and experience programs in establishing future operational strategies for arboretums and botanical gardens.

\section{References}

Chang, J.Y. 2015. Convergence of education and information \& communication technology: A study on the communication characteristics of SNS affecting relationship development between professor and student. J. Korea Converg. Soc. 6(6):213-219. https://doi.org/10.15207/J KCS.2015.6.6.213

Choi, S. and K.H. Choi. 2015. Achievement and satisfaction research of the undergraduate orchestra club activities: A convergent aspects of statistical method and opinion mining. J. Korea Converg. Soc. 6(4):25-31. 
https://doi.org/10.15207/JKCS.2015.6.4.025

Choi, Y.S. and H.M. Kim. 2016. The influence of public diplomacy with social media on country image and country brands: Focusing on cultural contents. J. Korea Contents Assoc. 16(3):426-438. https://doi.org/10.5392/JKCA.20 16.16.03.426

Chun, H. 2015. The comparison of coauthor networks of two statistical journals of the Korean Statistical Society using social network analysis. J. Korean Data Inf. Sci. Soc. 26(2):335-346. https://doi.org/10.7465/jkdi.2015.2 6.2 .335

Hong, J.S. and I.K. Oh. 2016 Image difference of before and after an incident using social big data analysis: Focusing on a ramp return of ' $\mathrm{K}$ ' airline. Int. J. Tour. Hosp. Res. 30(6):119-133. https://doi.org/10.21298/IJT HR.2016.06.30.6.119

Hong, Y. 2014. A study on the invigorating strategies for open government data. J. Korean Data Inf. Sci. Soc. 25(4):769-777. https://doi.org/10.7465/jkdi.2014.25.4.769

Jang, J.Y. 2013. Automatic retrieval of SNS opinion document using machine learning technique. J. Inst. Internet Broadcast. Commun. 13(5):27-35. https://doi.org/10.72 36/JIIBC.2013.13.5.27

Kang, S.G. 2012. A study on the classification and management measures of arboreta in Korea. Doctoral dissertation, Kyungpook National University, Daegu, Korea.

Kang, S.N., Y.S. Kim, and S.H. Choi. 2015. Study on the social issue sentiment classification using text mining. J. Korean Data Inf. Sci. Soc. 26(5):1167-1173. https://doi.org/10.7465/jkdi.2015.26.5.1167

Kim, D.Y., J.W. Park, and J.H. Choi. 2014. A comparative study between stock price prediction models using sentiment analysis and machine learning based on SNS and news articles. J. Inf. Technol. Serv. 13(3):221-233. https://doi.org/10.9716/KITS.2014.13.3.221

Lee, A.R., J.S. Bang, and Y.H. Kim. 2015. A design of a TV advertisement effectiveness analysis system using SNS big-data. KIISE Trans. Comput. Pract. 21(9):579-586.
https://doi.org/10.5626/KTCP.2015.21.9.579

Lee, Y.H. 2008. A study on the landscape management methods by the characteristics of the visual preference of forest landscape: Focused on Korea National Arboretum. Master's thesis, Kookmin University, Seoul, Korea.

Lee, Y.J., J.H. Seo, and J.T. Choi. 2014. Fashion trend marketing prediction analysis based on opinion mining applying SNS text contents. J. Korean Inst. Inf. Technol. 12(12):163-170. https://doi.org/10.14801/jkiit.2014.12.1 2.163

Lim, H.J. and S.H. Park. 2015. A tentative approach for regional futures strategy with big data, - through the analysis using the data of SNS and newpaper. J. Korean Cadastre Inf. Assoc. 17(1):75-90.

Oh, H.J. 2016. A study on the effects of choice attributes for healing tourism on value, attitude and satisfaction; Focus on the scale development for healing tourism. Doctoral dissertation, Kyungsung University, Pusan, Korea.

Oh, I.K., T.S. Lee, and C.N. Chon. 2015. A study on awareness of Korea tourism through big data analysis. J. Tour. Sci. 39(10):107-126. https://doi.org/10.17086/J TS.2015.39.10.107.126

Seo, J.Y. and C. Koh. 2014. Big data analysis by sensitivity analysis. J. Soc. Converg. Knowl. 2(1):15-21.

Song, K.S., H.Y. Noh, and S.J. Lee. 2015. Recommendation of emotion-based service by using SNS: A case of movie industry. J. Korea Manag. Eng. Soc. 20(2):91-104.

Song, T.M., J. Song, and M.K. Cheon. 2015. Predicting tobacco risk factors by using social big data. J. Korean Data Inf. Sci. Soc. 26(5):1047-1059. https://doi.org/10.7 465/jkdi.2015.26.5.1047

Woo, K.S. and J.H. Suh. 2017. Urban landscape image study by text mining and factor analysis: Focused on Lotte World Tower. J. Korean Inst. Landsc. Archit. 45(4):104-117. https://doi.org/10.9715/KILA.2017.45.4.104 